\title{
A Study on Structural Performance of Non-Prismatic Girders with Double Corrugated Stiffened Steel and Composite Webs
}

\author{
Saranya Radhakrishnan M \\ Post Graduate Student, \\ Department of Civil Engineering \\ Sree Narayana Gurukulam College of Engineering \\ Ernakulam, Kerala, India
}

\author{
Binu P \\ Associate Professor, \\ Department of Civil Engineering \\ Sree Narayana Gurukulam College of Engineering \\ Ernakulam, Kerala, India
}

\begin{abstract}
There are some limitations to the use of conventional flat plate web steel girders such as poor web stability and low buckling strength. To overcome these kinds of problems, the idea of using steel corrugated webs to girders has been introduced for achieving enhanced structural performance. The existing studies on bridge girders with steel corrugated webs are focused on single corrugated web girders only. According to previous researches, large forces generated on the girders result in buckling of single corrugated web. This paper focuses on Double corrugated web girders. The Double corrugated web girders can be strengthen either by providing stiffeners along with the corrugated web or by making the web as a composite one.This paper consists of investigations on Non- prismatic girders with Double Corrugated Stiffened Steel Web (DCSSWG) consist of two stiffened corrugated steel webs with steel flanges and also on Non- prismatic girders with Double Corrugated Composite Web (DCCWG) having UltraLightweight Cement Composite(ULCC) fill in the space between two corrugated steel webs. Structural performance of Single and Dual Non-prismatic girders with Double Corrugated Stiffened Steel Webs and Double Corrugated Composite Webs having different tapered ratios are investigated using ANSYS 16.1 software. The results obtained from the study have shown that Non prismatic girders with Double Corrugated Composite Webs show more strength and load carrying capacity as compared to Double Corrugated Stiffened Steel Webs for the same tapered ratio. The effect of Flat flanges (FF), Hollow flanges (HF) and Composite flanges (CF) on the performance of Non prismatic girder with Double Corrugated Composite Webs was also investigated under its static structural performance. The results showed that, Double Corrugated Composite webs in girders with Ultra- Lightweight Cement Composite filled Hollow Section Flanges or Composite Flanges showed better strength, better load carrying capacity than that of Flat Flanges and Hollow Flanges.
\end{abstract}

Keywords-Tapered ratio, Non- prismatic girder, Corrugated web

\section{INTRODUCTION}

Bridge girders with corrugated webs have a number of advantages such as more out- of plane stiffness, higher buckling resistance and shear capacity, excellent strength and web stability than that of conventional flat web girders. Some examples of bridges provided with corrugated steel web girders are the Maupré Bridge constructed in France and the Hondani Bridge constructed in Japan. According to previous researches, large forces generated on the girders result in buckling of single corrugated steel webs. For improving its strength and web stability, Double corrugated webs can be provided. That is, the girder will consist of two corrugated steel webs which are placed parallel and separated by a small gap in between them. So that the web portion will be thick The present study focuses on Double corrugated web girders. The purpose of this paper is to obtain numerical modelling results on Single and Dual linearly tapered girders (Nonprismatic girders) with Double corrugated webs. A tapered girder is wider at one end than the other, giving a tapered appearance to the member and the term Tapered ratio is the ratio between maximum web height to minimum web height of tapered girders (Non-prismatic girders). In this paper the effect of Flat Flanges (FF), Hollow flanges (HF) and Composite flanges (CF) on the performance of Non prismatic girder with Double Corrugated Composite Webs (DCCWG) was also investigated.

\section{OBJECTIVES}

1. To investigate structural performance of Single Non prismatic Girders with Double Corrugated Stiffened Steel Webs and Double Corrugated Composite Webs for different tapered ratios.

2. To investigate structural performance of Dual Non prismatic Girders with Double Corrugated Stiffened Steel Webs and Double Corrugated Composite Webs for different tapered ratios.

3. To investigate the effect of different types of flanges on the structural performance of Dual Non - prismatic Girder with Double Corrugated Composite Webs.

\section{SUMMARY OF LITERATURE REVIEW}

B. Kovesdi, L. Dunai [3] conducted investigations on prismatic single corrugated web girders and patch load resistance was determined. it was showed that loading length, flat flange thickness and also girder span have a significant effect on patch loading resistance and buckling strength of girders. B. Kovesdi et al. [4] investigated Interacting stability behavior of steel I-girders with single corrugated steel webs. The results showed that interacting stability depended more on ratio of flange to corrugated web patch loading resistance of prismatic steel I-girders. M. F. Hassanein, O.F. Kharoob [11] conducted study on the single corrugated steel webs of tapered 
bridge girders. From the study, the increase in shear strength was found to be linear with the web thickness increment of the linearly tapered corrugated steel webs. E. Zevallos et al. [5] presented a study on shear performance of tapered web panels of the linearly tapered bridge girders with single corrugated steel webs. It was observed that web thickness of girders has a greater influence on their shear behaviour. Sihao Wang et al. [13] conducted study on prismatic steel I-girders with single corrugated webs for various stiffener arrangements. From the study it can be observed that strength and stability of corrugated web with vertical stiffeners was more than that of horizontal stiffeners.

\section{NUMERICAL EVALUATION USING ANSYS 16.1}

Numerical models for the study were developed with the Finite Element program ANSYS WORKBENCH 16.1 and the results obtained were compared each other and final inference was made.

\section{A. Numerical Evaluation on Single Non-prismatic girders}

Numerical models for Single Non - prismatic girders are developed with the Finite Element program ANSYS 16.1. Numerical modelling of three types of Single Non -prismatic girders were performed - (1) Single Non-prismatic Girder with Double Corrugated Web (No additional stiffeners or no additional material is provided with corrugated web portion of girder), (2) Single Non - prismatic Girder with Double Corrugated Stiffened Steel Web (Here stiffeners are provided in between two Corrugated webs), (3) Single Non prismatic Girders with Double Corrugated Composite Webs (An additional material Ultra- Lightweight Cement Composite (ULCC) fill is provided along with two corrugated webs). The performance of these three kinds of Single Non - prismatic girders was investigated under 4 different tapered ratios of corrugated web such as 1.5, 2,3 and 4 also. All girders were modelled with SHELL 181 elements. The length of three kinds of Single Non -prismatic girders is $4500 \mathrm{~mm}$. Thickness of flat flange is adopted as $20 \mathrm{~mm}$ and thickness of corrugated web is $6 \mathrm{~mm}$. Width of flange is taken as $225 \mathrm{~mm}$. Height of web is selected according to the tapered ratio of web shown in Table 1. The average height of corrugated web for each model is about $500 \mathrm{~mm}$ and weight of girder for each tapered ratio was adjusted to be the same. The geometric details of the corrugated web portion for all type of girder are shown in Fig.1.

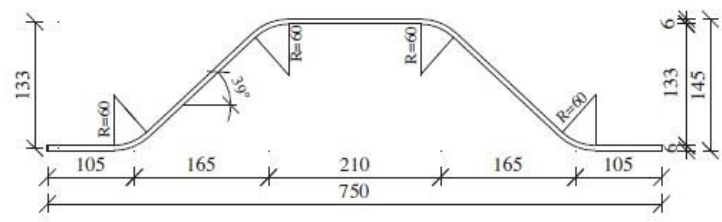

Fig. 1. The geometric properties of corrugated web [3]

TABLE 1 Tapered ratios of Corrugated web

\begin{tabular}{|c|c|c|}
\hline $\begin{array}{l}\text { Tapered ratio of } \\
\text { web }\left(h_{1} / h_{2}\right)\end{array}$ & $\begin{array}{c}\text { Height of web } \\
h_{1}(\mathrm{~mm})\end{array}$ & $\begin{array}{c}\text { Height of web } \\
\mathrm{h}_{2}(\mathrm{~mm})\end{array}$ \\
\hline 1.5 & 600 & 400 \\
\hline 2 & 670 & 335 \\
\hline 3 & 750 & 250 \\
\hline 4 & 800 & 200 \\
\hline
\end{tabular}

The girders are simply supported at both ends and the two points symmetric loading was applied along the total width of the flange by two loading plates. Geometry of Single Nonprismatic Girder is shown in Fig. 2. The performance of Single Non - prismatic Girders with Double Corrugated Web can be improved by means of providing stiffeners with same thickness of web $6 \mathrm{~mm}$ at suitable intervals as shown in Fig.3. The strengthening of the Single Non-prismatic girder with Double Corrugated Web can be also done by means of making the web portion as a composite one by providing ULCC fill at the hollow space in between two corrugated steel webs as shown in Fig 4. Material properties for steel components and ULCC are shown in Table 2.

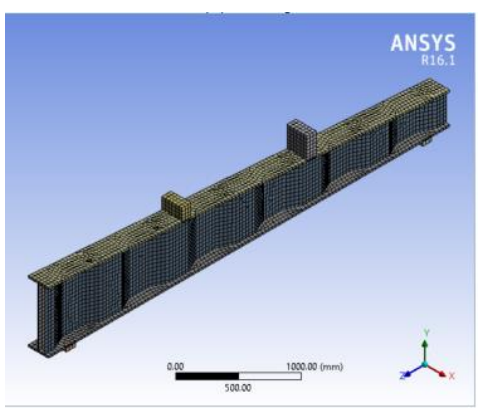

Fig. 2. Single Non-prismatic Girder

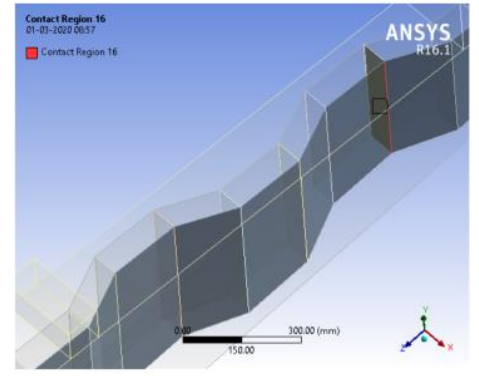

Fig.3. Double Corrugated Stiffened Steel Web

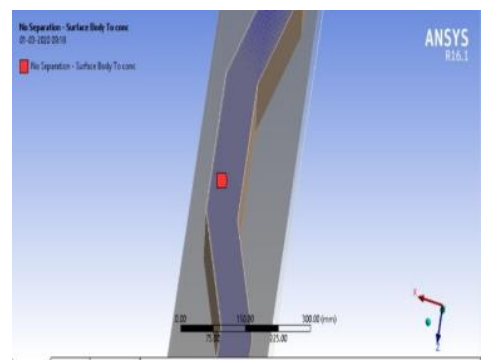

Fig. 4. Double Corrugated Composite Webs

TABLE 2 Material properties of Non - prismatic Girders

\begin{tabular}{|l|l|}
\hline \multicolumn{1}{|c|}{ Properties } & \multicolumn{1}{|c|}{ values } \\
\hline Modulus of Elasticity of Steel & $2 \times 10^{5} \mathrm{~N} / \mathrm{mm}^{2}$ \\
\hline Poisson's Ratio of Steel & 0.3 \\
\hline Yield strength of Steel & $379 \mathrm{MPa}$ \\
\hline Density of Steel & $7860 \mathrm{~kg} / \mathrm{m}^{3}$ \\
\hline Modulus of elasticity of ULCC & $10.62 \mathrm{GPa}$ \\
\hline Poisson's Ratio of ULCC & 0.15 \\
\hline Density of ULCC & $1250 \mathrm{~kg} / \mathrm{m}^{3}$ \\
\hline
\end{tabular}


Fig 5, Fig 6 and Fig 7 show combined Load - Deflection curve for Single Non- prismatic Girders with Double Corrugated Web [DCWG], Single Non - prismatic Girder with Double Corrugated Stiffened Steel Web [DCSSWG], and Single Non prismatic Girders with Double Corrugated Composite Webs [DCCWG] obtained for four different tapered ratios. Ultimate Loads obtained for Single Nonprismatic Girders are shown in Table 3.

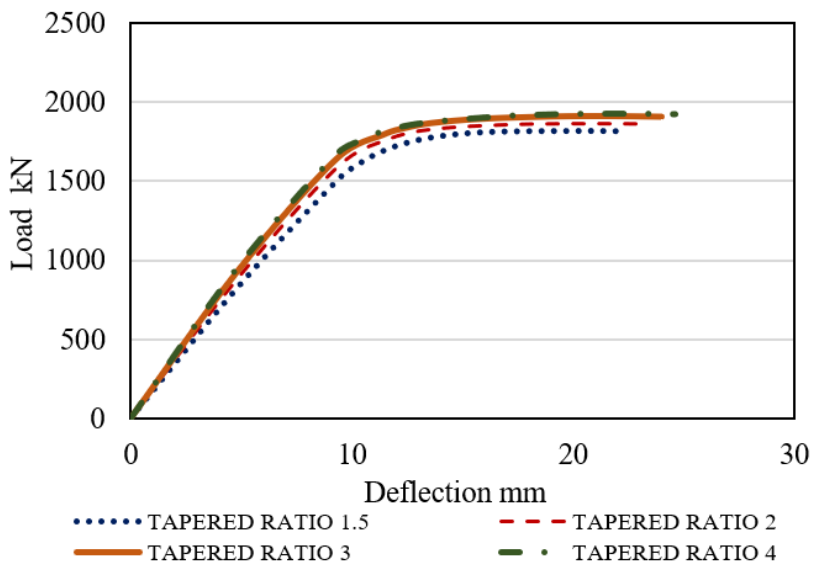

Fig. 5. Load - Deflection curve for Single Non - prismatic Girders with Double Corrugated Web [DCWG] for different tapered ratios

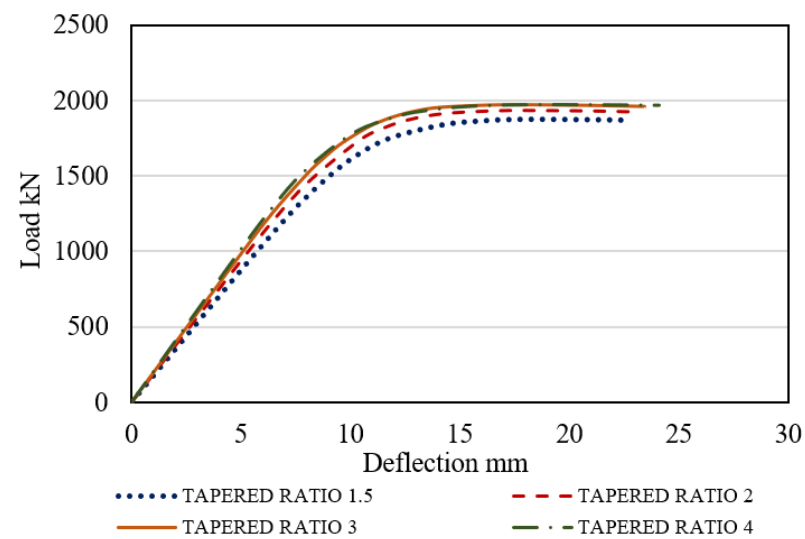

Fig.6. Load -Deflection curve for Single Non - prismatic Girders with Double Corrugated Stiffened Steel Web [DCSSWG] for different tapered ratios

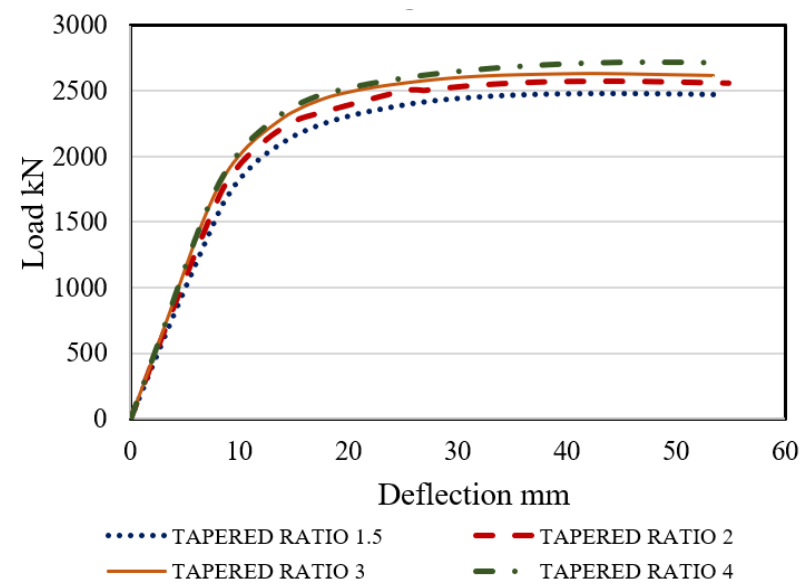

Fig .7. Load - Deflection curve for Single Non prismatic Girders with Double Corrugated Composite Web [DCCWG] for different tapered ratios
TABLE 3 Ultimate Load of Single Non-prismatic Girders

\begin{tabular}{|c|c|c|c|}
\hline \multirow{2}{*}{$\begin{array}{c}\text { Tapered } \\
\text { Ratio }\end{array}$} & \multicolumn{3}{|c|}{ Ultimate Load of Single Non-prismatic } \\
& \multicolumn{3}{|c|}{ Girders (kN) } \\
\cline { 2 - 4 } & $\begin{array}{c}\text { Single } \\
\text { DCWG }\end{array}$ & $\begin{array}{c}\text { Single } \\
\text { DCSSWG }\end{array}$ & $\begin{array}{c}\text { Single } \\
\text { DCCWG }\end{array}$ \\
\hline 1.5 & 1816.3 & 1875.8 & 2475.7 \\
\hline 2 & 1865.5 & 1934.6 & 2569.6 \\
\hline 3 & 1912.9 & 1969.5 & 2627.7 \\
\hline 4 & 1929.3 & 1974 & 2717.4 \\
\hline
\end{tabular}

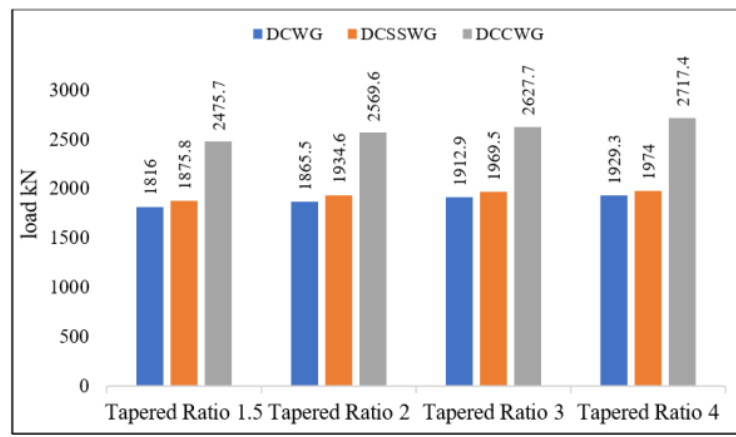

Fig .8. Comparison of results for Single Non- prismatic girders

From obtained results, it can be found that Single Nonprismatic Girders with Double Corrugated Composite Webs (DCCWG) show better strength and high load carrying capacity as compared to Single Non- prismatic Girders with Double Corrugated Stiffened Steel Webs (DCSSWG) for the same tapered ratio. In all cases load-carrying capacity is observed to be improved slightly with the increase in tapered ratio of steel corrugated web.

\section{B. Numerical Evaluation on Dual Non-prismatic Girders}

Numerical modelling of two types of Dual Non -prismatic girders were performed - (1) Dual Non - prismatic Girders with Double Corrugated Stiffened Steel Web (Here stiffeners are provided in between two Corrugated steel webs), (2) Dual Non - prismatic Girders with Double Corrugated Composite Webs (An additional material Ultra- Lightweight Cement Composite (ULCC) fill is provided along with two corrugated steel webs). The performance of these two types of Dual Non - prismatic girders are investigated under 3 different tapered ratios of corrugated web such as 2,3 and 4 also. The girders are simply supported at both ends and the two points symmetric loading was applied along the total width of the flange by two loading plates. Geometry of Dual Non-prismatic Girder is shown in Fig. 9. The performance of Dual Non prismatic Girders with Double Corrugated Web can be improved by means of providing stiffeners with same thickness of web $6 \mathrm{~mm}$ at suitable intervals as shown in Fig.3. The strengthening of the Dual Non-prismatic girder with Double Corrugated Web can be done by means of making the web portion as a composite one by providing ULCC fill at the hollow space in between two corrugated steel webs as shown in Fig 4. The material properties, geometric details and other dimensions except the length are same as in case of Single Non-prismatic girders. Here length of Dual girder was adopted as 9000mm. Fig 10 and Fig 11 show combined Load Deflection curve for Dual Non - prismatic Girders with Double Corrugated Stiffened Steel Web [DCSSWG] and Dual Non prismatic Girders with Double Corrugated Composite 
Webs [DCCWG] obtained for three different tapered ratios. Ultimate Loads obtained for Dual Non-prismatic Girders are shown in Table 4.

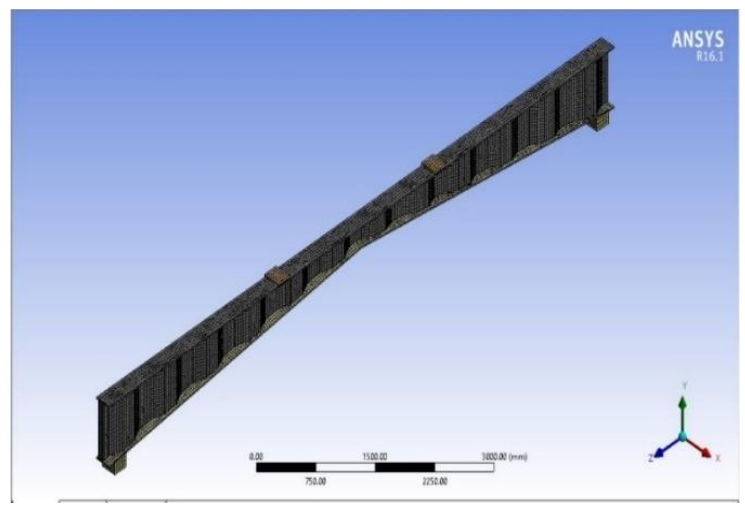

Fig.9. Dual Non-prismatic Girder

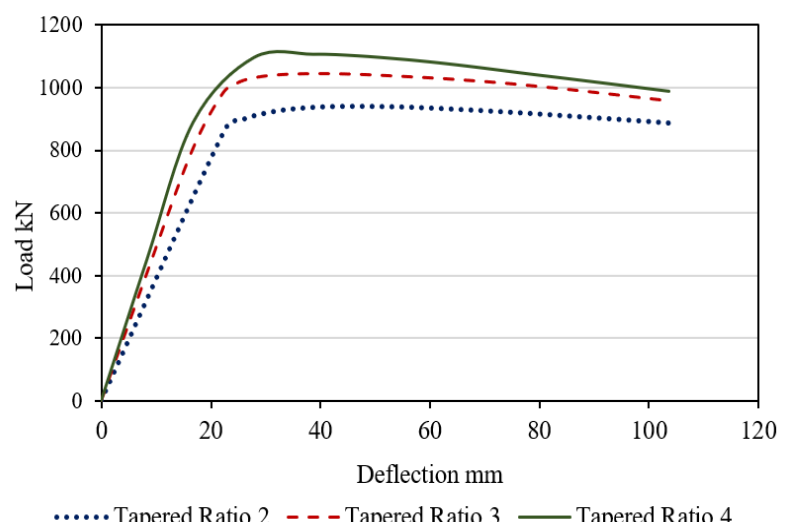

Fig.10. Load - Deflection curve for Dual Non-prismatic Girders with Double Corrugated Stiffened Steel Web [DCSSWG] for different tapered ratios

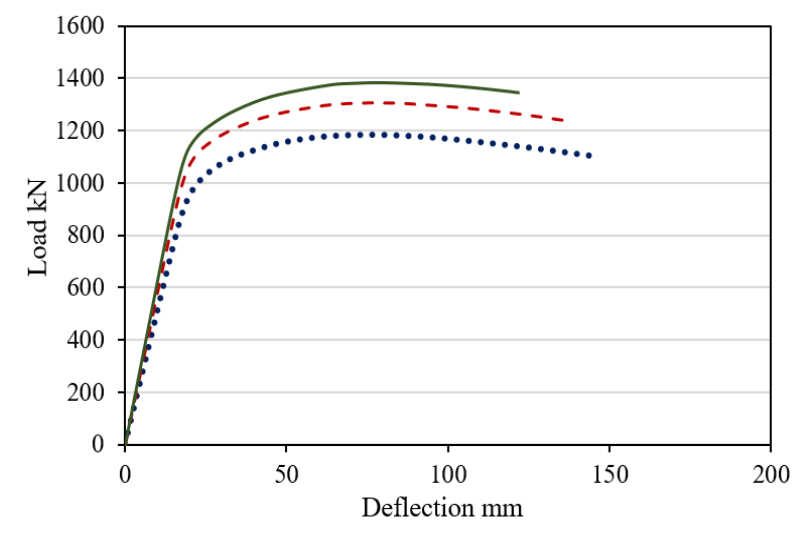

•.... Tapered Ratio $2 \quad$ - - - Tapered Ratio $3 \quad$ Tapered Ratio 4

Fig 11 Load- Deflection curve for Dual Non - prismatic Girders with Double Corrugated Composite Web [DCCWG] for different tapered ratios

TABLE 4 Ultimate Load of Dual Non-prismatic Girders

\begin{tabular}{|c|c|c|}
\hline \multirow{2}{*}{$\begin{array}{c}\text { Tapered } \\
\text { Ratio }\end{array}$} & \multicolumn{2}{|c|}{$\begin{array}{c}\text { Ultimate Load of Dual Non-prismatic } \\
\text { Girders (kN) }\end{array}$} \\
\cline { 2 - 3 } & Dual DCSSWG & Dual DCCWG \\
\hline 2 & 941.32 & 1185.52 \\
\hline 3 & 1044.92 & 1303.48 \\
\hline 4 & 1107.74 & 1383.66 \\
\hline
\end{tabular}

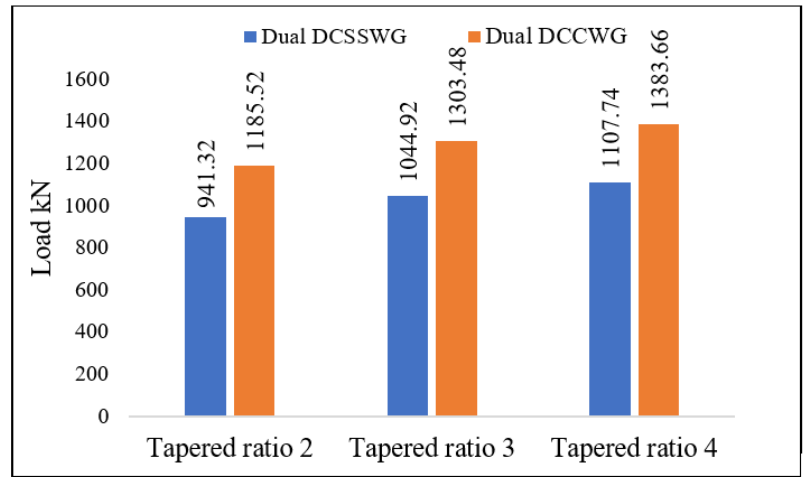

Fig.12. Comparison of results for Dual Non- prismatic girders

Result comparison for Dual Non - prismatic girders is shown is shown in Fig 12. Dual Non - prismatic Girder with Double Corrugated Composite Webs (DCCWG) shows better strength and high load-carrying capacity as compared to Dual Non - prismatic Girder with Double Corrugated Stiffened Steel Webs (DCSSWG) for the same tapered ratio. In all cases load-carrying capacity is observed to be improved slightly with the increase in tapered ratio of steel corrugated web.

\section{Numerical Evaluation on Different Flange Effects}

Dual Non-prismatic Girder with Double Corrugated Composite Web with tapered ratio 4 shows more strength and capacity. Here in order to investigate effect of flanges, Dual Non - prismatic Girder with Double Corrugated Composite Web (DCCWG) for tapered ratio 4 was considered in to account. Above mentioned model was created with steel flat flanges at both top and bottom having thickness of $20 \mathrm{~mm}$ and with a weight of $159 \mathrm{~kg}$ in second objective. In order to investigate the effect of Hollow Flanges (HF) on the performance of Dual DCCWG, two kinds of models were created. First one was Dual Non - prismatic Girder with Double Corrugated Composite Web [DCCWG] having Hollow Flange (HF) at top and Flat Flange (FF) at bottom and 2nd type was Dual Non - prismatic Girder with Double Corrugated Composite Web [DCCWG] having Hollow Flange (HF) at bottom and Flat Flange (FF) at top. Tapered ratio for both two kinds of models was selected as four. The thickness of Hollow Flange (HF) was adjusted to be $50 \mathrm{~mm}$ in such a way that weight of flat flange and hollow flange are remaining to be the same, equal to $159 \mathrm{~kg}$. In order to investigate the effect of Composite Flanges (CF) on the performance of Dual DCCWG, two kinds of models were created. First one was Dual Non - prismatic Girder with Double Corrugated Composite Web [DCCWG] having Composite Flange (CF) at top and Flat Flange (FF) at bottom and 2nd type was Dual Non - prismatic Girder with Double Corrugated Composite Web [DCCWG] having Composite Flange (CF) at bottom and Flat Flange (FF) at top. The CF can be defined as ULCC filled Hollow Section Flange (HSF). The composite material ULCC was filled within the Hollow Flange to create Composite Flange. The geometric properties, material properties and other dimensions were taken as in previous case of Dual Non prismatic Girder with Double Corrugated Composite Web with tapered ratio 4 . The meshed view of Non - prismatic Girder with Double Corrugated Composite Web [DCCWG] having Flat Flanges (FF) at bottom and top is shown in Fig 9. In other models one of the flat flanges was replaced by Hollow Flange or Composite Flange at top or bottom. Fig 13 
shows combined Load - Deflection curve for Dual Non prismatic Girders with Double Corrugated Composite Web [DCCWG] obtained for different flange types. The Ultimate load for each girder observed is shown in Table 5.

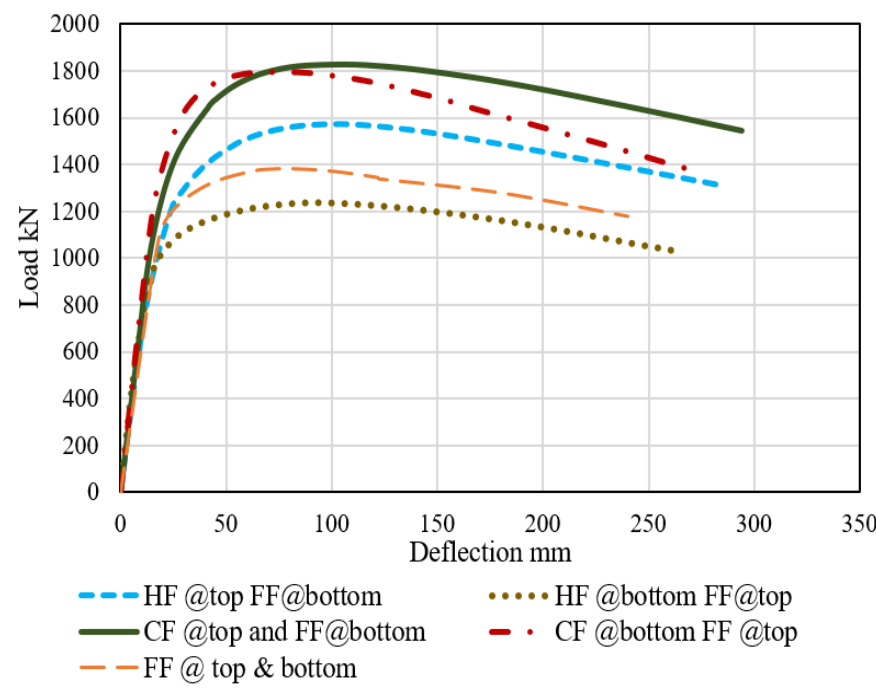

Fig.13. Load- Deflection curve for Dual Non - prismatic Girders with Double Corrugated Composite Web [DCCWG] for different flange types

TABLE 5 Ultimate loads for Dual Non prismatic Girders with Double Corrugated Composite Web [DCCWG] for different flange types

\begin{tabular}{|c|c|c|}
\hline Model Name & Load (kN) & $\begin{array}{l}\text { Deflection at } \\
\text { failure (mm) }\end{array}$ \\
\hline FF @ top \& bottom & 1383.66 & 80.016 \\
\hline HF @ top FF @ bottom & 1570.02 & 109.45 \\
\hline HF @ bottom FF @ top & 1237.9 & 87.26 \\
\hline CF @ top FF @ bottom & 1827.12 & 106.65 \\
\hline CF @ bottom FF @ top & 1793.36 & 83.706 \\
\hline
\end{tabular}

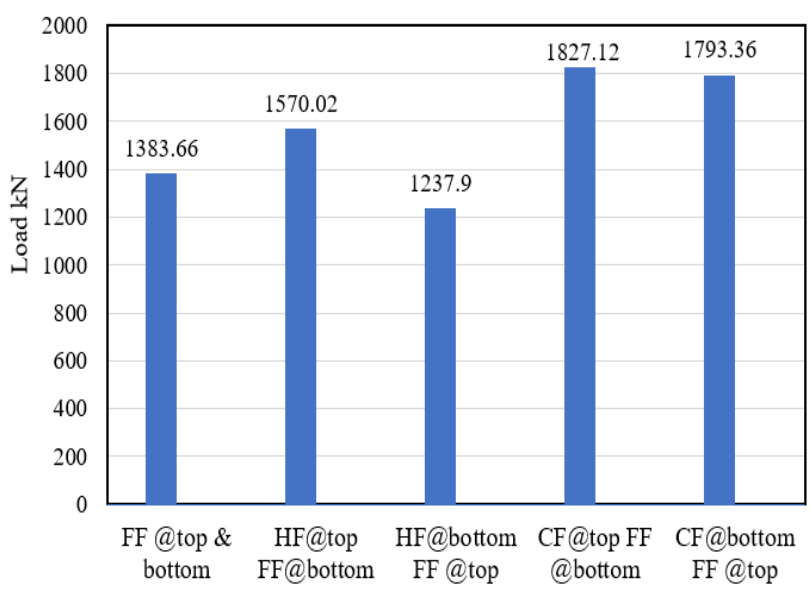

Fig.14. Ultimate loads for Dual DCCWG with different flange types

Adding Hollow Flange at top was resulted in the increase of load carrying capacity by an amount 13 percent than that of the Model with FF @ top and bottom. But adding Hollow flange at bottom resulted in 10 percent decrement in load carrying capacity. Load carrying capacity of the girder by adding Composite Flange at top was 1827.12 KN. About 32 percent improvement of load carrying capacity can be observed here. Adding Composite Flange at bottom was resulted in 29 percent increment of load carrying capacity than that of providing two Flat Flanges. While analyzing the results obtained, the Double Corrugated Composite Webs in girders with ULCC filled Hollow Section Flanges or Composite Flanges at top showed highest load carrying capacity. Results comparison for Dual Non-prismatic girders with different cases of flange types is shown in Fig 14.

\section{CONCLUSIONS}

The strengthening of Double Corrugated Web by means of providing stiffeners or by making the web portion as a composite one using a composite material was investigated analytically in this paper for different tapered ratios of web. The effect of Flat flanges, Hollow flanges and Composite flanges on the performance of Dual Non prismatic girder with Double Corrugated Composite Webs (DCCWG) was also analysed. The following conclusions are derived from this present paper:

- $\quad$ For both Single and Dual girders, the load carrying capacity and strength of Non - prismatic girders with Double corrugated steel webs are affected by tapered ratios of corrugated web. In all cases load-carrying capacity was observed to be improved slightly with the increase in tapered ratio of steel corrugated web of the Non-prismatic girder.

- The strength and load carrying capacity of both Single and Dual Non - prismatic girders with Double corrugated web can be improved by providing stiffeners in between the two corrugated webs or by making the web portion of the girder as a composite one by providing UltraLightweight Cement Composite fill (ULCC fill).

- Both Single and Dual Non prismatic girders with Double corrugated composite web possess more strength and stability and the rate of improvement of strength is excellent for composite web than that of stiffened steel web for the same tapered ratio.

- Adding Hollow Flange at top and flat flange at bottom of the girder resulted in improvement of load carrying capacity by 13 percent than that of Dual Non- prismatic girders with Double Corrugated Composite Web having two Flat Flanges. But adding Hollow flange at bottom results 10 percent decrement in load carrying capacity.

- $\quad$ Adding Composite Flange at top results in 32 percent improvement of load carrying capacity and at bottom results 29 percent increment in load carrying capacity than that of providing two Flat Flanges. The Double Corrugated Composite Webs in girders with ULCC filled Hollow Section Flanges or Composite flanges at top showed highest load carrying capacity and strength than that of other flanges for Dual Non-prismatic Girders.

\section{REFERENCES}

[1] A.M. El Hadidy, M.F. Hassanein, M. Zhou , "The effect of using tubular flanges in bridge girders with corrugated steel webs on their 
shear behaviour - A numerical study," Thin-Walled Structures, 124, 121-135, 2018.

[2] B. Jáger, L. Dunai, B. Kövesdi, "Flange buckling behavior of girders with corrugated web Part I: Experimental study," Thin-Walled Structures, 118,181-195,2017.

[3] B. Kovesdi, L. Dunai, "Determination of the patch loading resistance of girders with corrugated webs using nonlinear finite element analysis," Computers and Structures, 89, 2010 - 2019 , 2011.

[4] B. Kovesdi, L.Dunai a, U. Kuhlmann, "Interacting stability behaviour of steel I - girders with corrugated webs," Thin-Walled Structures, 61, 132-144, 2012.

[5] E.Zevallos, M.F. Hassanein, E. Real, E. Mirambell, "Shear evaluation of tapered bridge girder panels with steel corrugated webs near the supports of continuous bridges," Engineering Structures, 113, 49-159, 2016.

[6] Jian-Guo Nie, Li Zhu, Mu-Xuan Tao, Liang Tang, "Shear strength of trapezoidal corrugated steel webs," Journal of Constructional Steel Research, 85 ,105-115, 2013.

[7] Jun He, Sihao Wang, Yuqing Liu, Zhan Lyu, Chuanxi Li, "Mechanical Behavior of a Partially Encased Composite Girder with Corrugated Steel Web: Interaction of Shear and Bending", Engineering, ELSEVIER, 3, 806-816, 2017.

[8] Jun He, Yuqing Liu, Zhaofei Lin, Airong Chen, Teruhiko Yoda, "Shear behavior of partially encased composite I-girder with corrugated steel web: Numerical study," Journal of Constructional Steel Research, 79, 166-182, 2012.
[9] Jun He, Yuqing Liu, Airong Chen, Dalei Wang, Teruhiko Yoda,“ Bending behavior of concrete - encased composite I-girder with corrugated steel web," Thin-Walled Structures,74, 70-84, 2014.

[10] M.E.A.-H. Eldib, "Shear buckling strength and design of curved corrugated steel webs for bridges," Journal of Constructional Steel Research, 65, 2129-2139, 2009.

[11] M.F. Hassanein, O.F. Kharoob, "Shear buckling behavior of tapered bridge girders with steel corrugated webs," Engineering Structures, 74, 157-169, 2014.

[12] Moussa Leblouba, Samer Barakat, Zaid Al-Saadon, "Shear behavior of corrugated web panels and sensitivity analysis," Journal of Constructional Steel Research, 151, 94-107, 2018.

[13] Sihao Wanga, Jun Heb, Yuqing Liu, "Shear behavior of steel I- girder with stiffened corrugated web, Part I: Experimental study," ThinWalled Structures, 140, 248-262, 2019.

[14] Tong Guo, Richard Sause, "Analysis of local elastic shear buckling of trapezoidal corrugated steel webs," Journal of Constructional Steel Research, 102,59-71, 2014.

[15] Jun-Yan Wang, Xiao-Long Gao, Jia-Bao Yan, "Developments and mechanical behaviors of steel fiber reinforced ultra- lightweight cement composite with different densities," Construction and Building Materials, 171,643-653, 2018. 